\title{
Ten years later: Evaluation of the effectiveness of $12.5 \%$ amitraz against a field population of Rhipicephalus (Boophilus) microplus using field studies, artificial infestation (Stall tests) and adult immersion
} \section{tests}

\author{
Willian Giquelin Maciel ${ }^{\mathrm{a}}$, Welber Daniel Zanetti Lopes ${ }^{\mathrm{a}, \mathrm{b}, *}$, Breno Cayeiro Cruz ${ }^{\mathrm{a}}$, \\ Lucas Vinicius Costa Gomes ${ }^{a}$, Weslen Fabrício Pires Teixeira ${ }^{a}$, Carolina Buzzulini ${ }^{a}$, \\ Murilo Abud Bichuette ${ }^{a}$, Gabriel Pimentel Campos ${ }^{a}$, Gustavo Felippelli ${ }^{a}$, \\ Vando Edésio Soares ${ }^{a}$, Gilson Pereira de Oliveira ${ }^{a}$, Alvimar José da Costa ${ }^{a}$ \\ a CPPAR-Animal Health Research Center, Faculdade de Ciências Agrárias e Veterinárias, UNESP, Campus de Jaboticabal, Via de Acesso Prof. Paulo Donatto \\ Castellane, $s / n^{\circ}$ CEP: 14884-900, Jaboticabal, São Paulo, Brazil \\ b Instituto de Patologia Tropical e Saúde Pública, Universidade Federal de Goiás, Goiânia, Goiás 74605050, Brazil
}

\section{A R T I C L E I N F O}

\section{Article history:}

Received 17 June 2015

Received in revised form 22 October 2015

Accepted 23 October 2015

\section{Keywords:}

Artificial infestations

Natural infestation

Resistance

Spray formulations

Stall test

\begin{abstract}
A B S T R A C T
Using field trials, artificial infestations (Stall tests) and in vitro adult immersion tests, the present study evaluated the acaricidal efficacy of $12.5 \%$ amitraz administered via whole body spraying against a Rhipicephalus (Boophilus) microplus population that did not have any contact with chemical products belonging to this acaricide family for 10 years (approximately 40 generations). Two natural infestation trials, two artificial infestation trials (Stall tests) and two adult immersion tests were performed in two different stages in 2005 and 2015. Between 2002 and 2015, the bovine herd of this property was formed by approximately 450 animals from the Simmental breed that were divided into nine paddocks formed by Cynodon dactylon (L.) Pers. For the natural infestation experiments in 2005 and 2015, we selected nearly 70 animals naturally infested with ticks from the same herd that belonged to the "São Paulo" farm located in São José do Rio Pardo, São Paulo, Brazil. Field studies were performed in the same paddock (9). To evaluate anti-R. (B.) microplus activity in the artificially infested cattle (Stall tests) and adult immersion tests, two experiments of each methodology were performed at CPPAR (the Center of Research in Animal Health located on the FCAV/UNESP campus in Jaboticabal, São Paulo, Brazil) in 2005 and 2015. $R$. (B.) microplus used in the artificial infestation, and adult immersion test experiments were obtained from paddocks 1-9 in 2005 and 2015 from the commercial farm where the field studies were performed. Based on the obtained results, it was possible to conclude that amitraz use in rotation with pyrethroids every 28 days for three consecutive years (2002-2004) previous to the beginning of the first trial (2005) was sufficient to generate a $R$. (B.) microplus strain resistant to amitraz. Moreover, using field trials, artificial infestations (Stall tests) and adult immersion tests, we verified that 40 generations of the tick species with no contact to the aforementioned compound (amitraz) were not sufficient to revert or modify the efficacy/resistance of amitraz for this analyzed $R$. (B.) microplus strain. The reversion of amitraz efficacy values in $R$. (B.) microplus may only occur when resistance of the field strain is incipient. Alternatively, the differences in the results may be due to differences in the Rhipicephalus spp. species between current study locations. Therefore, future studies must be performed to prove this hypothesis.
\end{abstract}

(c) 2015 Elsevier B.V. All rights reserved.

\footnotetext{
* Corresponding author at: CPPAR-Animal Health Research Center. Faculdade de Ciências Agrárias e Veterinárias, UNESP, Campus de Jaboticabal, Via de Acesso Prof. Paulo Donatto Castellane, s/n CEP: 14884-900, Jaboticabal, São Paulo, Brazil. Fax: +55 1632092605 .

E-mail addresses: wdzlopes@hotmail.com,wdzlopes@fcav.unesp.br (W.D.Z. Lopes).

http://dx.doi.org/10.1016/j.vetpar.2015.10.024

0304-4017/@ 2015 Elsevier B.V. All rights reserved.
}

\section{Introduction}

Rhipicephalus (Boophilus) microplus is a transformer agent of blood in eggs and represents a major problem for the cattle industry (Maza et al., 2013). As a consequence of its feeding habits (hematophagy), this ectoparasite can lead to severe reductions in 
livestock productivity and cattle breeding, mainly due to anemia, disease transmission, reduced weight gain, excessive cost to the producers and even death of highly infested animals (Lopes et al., 2013).

The main tool available to control this ectoparasite is the use of synthetic chemical compounds (acaricides) (Pereira et al., 2008). In accordance with Cruz et al. (2015) and Gomes et al. (2015), the control of this ectoparasite using these chemical products is a key factor in improving production, but efforts to combat ticks on most cattle farms are performed incorrectly and are characterized by the excessive and disordered use of therapeutic approaches. In turn, this excessive usage increases production costs and accelerates the selection of parasite resistance, which represents a very significant (if not the primary) economic issue in animal production (Corrêa et al., 2015).

Amongst the available chemical groups, organophosphates, pyrethroids, amidines, macrocyclic lactones, phenylpyrazole and benzoylphenyl urea derivates stand out (Cruz et al., 2014a,b). Amitraz is a formamidine acaricide that is applied to cattle in plunge dips and spray races to control the cattle tick $R$. (B.) microplus. This compound is the most commonly used acaricide in some regions of Brazil (Vargas et al., 2003; Farias et al., 2008; Santos et al., 2009). It has some advantages over other acaricides, such as low toxicity to cattle and short withdrawal periods for milk (one day) and meat (14 days).

Several researchers (Foil et al., 2004; Furlong et al., 2007; Jonsson et al., 2010; Spagnol et al., 2010) demonstrated that the only acaricide group in which a resistance reversion was possible was the amidine class. According to these authors, there is a possibility for the reutilization of this formamidine after a few tick generations (15-20 generations) without contact with products of this family or following the use of amitraz in a rotation system with other acaricide classes. For this reason, the present study used field trials, artificial infestations (Stall tests) and adult immersion tests to evaluate the acaricidal efficacy of $12.5 \%$ amitraz administered through whole body spraying against a $R$. (B.) microplus population that lacked any contact with active principles belonging to this ectoparasiticide class for 10 years (approximately 40 generations).

\section{Material and methods}

2.1. Location and history of chemical compound use against $\mathrm{R}$.

(B.) microplus in the farm where the field trials were performed

From 2002 to 2015 when the second field trial was conducted, the bovine herd of this particular farm was formed by approximately 450 animals from the Simmental breed. These animals were housed in nine paddocks formed by Coast cross grass, as seen in Fig. 1. This farm has not purchased animals from other properties since 1994, and each paddock is occupied and grazed continuously without any animal-free paddocks during the entire year.

According to the owner's records, $R$. (B.) microplus control with chemical products started in a significant manner in 2001. Any bovine that reached high infestation levels was treated with a cypermethrin-based pulverization (Barrage ${ }^{\circledR}$, Zoetis Animal Health). In an attempt to initiate strategic control measures, all animals from the herd were treated against this tick species every 28 days between January 2002 and December 2004 with intercalated whole body spraying of amitraz (Triatox ${ }^{\circledR}$, MSD Animal Health) and cypermethrin (Barrage ${ }^{\circledR}$, Zoetis Animal Health) independent of each animal's infestation level. This strategic control scheme was finalized in December 2004. Between 2005 and 2015 (when the second stage of the present study was performed), the farm started to use different chemical products against the Southern Cattle Tick that were based on phenylpyrazole (fipronil), macrocyclic lactones (mainly ivermectin and doramectin) and benzoylphenyl ureas (fluazuron). These treatments were performed only when employees visually detected ticks present on the animals and lots. No amidines (amitraz) were administered in any treatments performed between 2005 and 2015.

\subsection{Field trials with natural R. (B.) microplus infestations}

Two different trials were conducted to evaluate the effect of $12.5 \%$ amitraz administered via whole body spraying against $R$. (B.) microplus in naturally infested cattle: the first in February 2005 and the second in January 2015. For each experiment, a single paddock (9) that belonged to the "São Paulo" farm (located in São José do Rio Pardo, São Paulo, Brazil) was utilized. This paddock contained approximately 50 animals, and all animals were naturally infested with ticks. We selected 20 animals in both experiments; all of the animals were 12- to 13-month-old Simmental males. Animal selection was based on an average of three consecutive counts of fully engorged $R$. (B.) microplus females between 4.5 and $8.0 \mathrm{~mm}$ in length located on the left side of each animal's body (Wharton and Utech, 1970). Selected bovines had no contact with any antiparasitic drugs for a minimum of 90 days prior to the beginning of the trials. Animals were randomly designated to treatment groups according to a randomized block design. The block formation was based on the arithmetic means of female ticks $(4.5-8.0 \mathrm{~mm}$ long) counted on three consecutive days ( $-3,-2$, and -1$)$. Cattle were divided into 10 blocks with 2 animals each, and inside each block the animals were randomly placed into one of the treatment groups: 10 animals were selected to be untreated controls and 10 animals were treated via whole body spraying with $12.5 \%$ amitraz. Prior to the pre-treatment tick counts, the cattle were maintained in a common paddock. However, after treatment paddock 9 was subdivided into two equal parts so that none of the groups would have any form of contact with animals from the other group during the entire post-treatment period. Both experiments (2005 and 2015) were conducted in the same paddock (number 9, displayed in Fig. 1).

To determine the therapeutic and residual efficacies obtained by the tested formulation, tick counts were performed on days 3 , 7, 14, 21 and 28 post-treatment (Wharton and Utech, 1970).

\subsection{Stall tests with artificial R. (B.) microplus infestations}

To evaluate the anti-R. (B.) microplus activity in artificially infested cattle, two experiments were performed at CPPAR (the Center of Research in Animal Health), which is located on the FCAV/UNESP campus in Jaboticabal, São Paulo, Brazil.

In each experiment (2005 and 2015), nearly 500 fully engorged female ticks were collected from the body surfaces of bovines from all paddocks of the property (1-9) during the tick counts performed prior to treatment (days -3,-2 and -1). These specimens were transported to CPPAR/FCAV/UNESP, where a laboratory colony of this particular $R$. (B.) microplus strain was initiated for posterior use in the artificial infestation trials. One colony was started in 2005 and used in the first study, while a second colony was started in 2015 and used for the second trial. During the experiments, the ticks were maintained in CPPAR using experimental bovines and a BOD incubator.

A total of 12 crossbred animals that were approximately seven months old and had not received any type of antiparasitic medication for a minimum of 120 days before the experiment were selected for each trial; the animals were identified using individually numbered ear tags. Each animal was kept in an individual suspended box that was appropriate for the Stall tests starting 27 days before treatment to allow for acclimatization. After the acclimation period, all animals were infested with 5000 R. (B). microplus 
larvae ( $0.25 \mathrm{~g}$ of eggs) with ages ranging from 14 to 28 days on the following experimental dates: $-24,-21,-19,-17,-14,-12,-10$, $7,-5,-3$ and -1 (considering day 0 as the treatment day) (Brazil, 1997). The infestation of cattle was performed using the following procedure. The stall door was opened and the animal was identified. Then, the animals were humanely restrained with a halter and infested with ticks in the stall. The syringes containing the larvae were applied over the dorsal line of the animal, and the larvae were allowed to move into the coat to settle. The total confinement time for each animal was approximately $60 \mathrm{~min}$. On days -3 , -2 and -1 (with day 0 defined as the treatment day), counts of fully engorged female ticks that naturally detached from each animal were performed.

The cattle were randomized and distributed to treatment groups according to the average number (arithmetic means) of fully engorged $R$. (B.) microplus females that detached from each animal. The animals were separated into 6 blocks with two animals each; within each block, individuals were randomly allocated to one of the following groups: 6 animals were used as untreated controls and 6 animals were treated via whole body spraying with $12.5 \%$ amitraz. The blocks were assigned to 2 sets of nearby pens, and animals within a block were allocated to pens within the set at random.

In both experiments with experimental infestations, daily counts of fully engorged female ticks that detached from each animal were performed from day 1 until day 28 post-treatment, always between 08:00 and 09:00 a.m. Additionally, all experimental animals were infested twice per week (Tuesdays and Thursdays) with approximately 5000 viable unfed larvae following the recommendations of Holdsworth et al. (2006).

\subsection{Treatment}

Treatment of the experimental animals in both trials (natural and artificial tick infestations) was performed using a hand pump with pressure in the "triangle format" so that each animal received treatment for 5 min with $5 \mathrm{~L}$ of solution containing $12.5 \%$ amitraz (Triatox ${ }^{\circledR}$, MSD Animal Health). For product administration, the animals were individually restrained with the aid of a rope that was tied so that there was no risk of hanging.

Products were diluted at a ratio of $40 \mathrm{~mL}$ of amitraz per 20 gallons of water according to the manufacturer's recommendations. After preparation, the dilution was subdivided into equal parts containing $5 \mathrm{~L}$, and the slurry was mixed thoroughly. The entire body of each animal was treated, including inside the ears, base of the horns, base of the tail, dewlap and inner face of the limbs and udder; all animals were dosed uniformly according to the product label specifications. Each animal received a mean dosage of $19 \mathrm{~mL} / \mathrm{kg}$ of the chemical compound.

After treatment and throughout the experiment, all animals were evaluated regarding the presence of clinical signs of systemic poisoning, such as ataxia, sialorrhea, prostration, excitement, convulsions, dysphonia, diarrhea, dyspnea, jaundice, cough, head tremors, skin tremors, and hyperesthesia.

\subsection{Efficacy}

For field trials with naturally infested animals and Stall tests evaluating artificially infested cattle, arithmetic means were selected to calculate the acaricide efficacies rather than geometric means according to the recommendations of Dobson et al. (2009), Vercruysse et al. (2011) and Lopes et al. (2014) using the following formula:

Efficacypercentage $=\left[1-\frac{\mathrm{Ta} \times \mathrm{Cb}}{\mathrm{Tb} \times \mathrm{Ca}}\right] \times 100$

In this equation, "Ta" is the number of fully or partially engorged female ticks counted on the treated animals after medication, "Tb" is the number of ticks counted on the treated animals during the 3 days prior to treatment, "Ca" is the number of fully or partially engorged female ticks counted on untreated control animals after

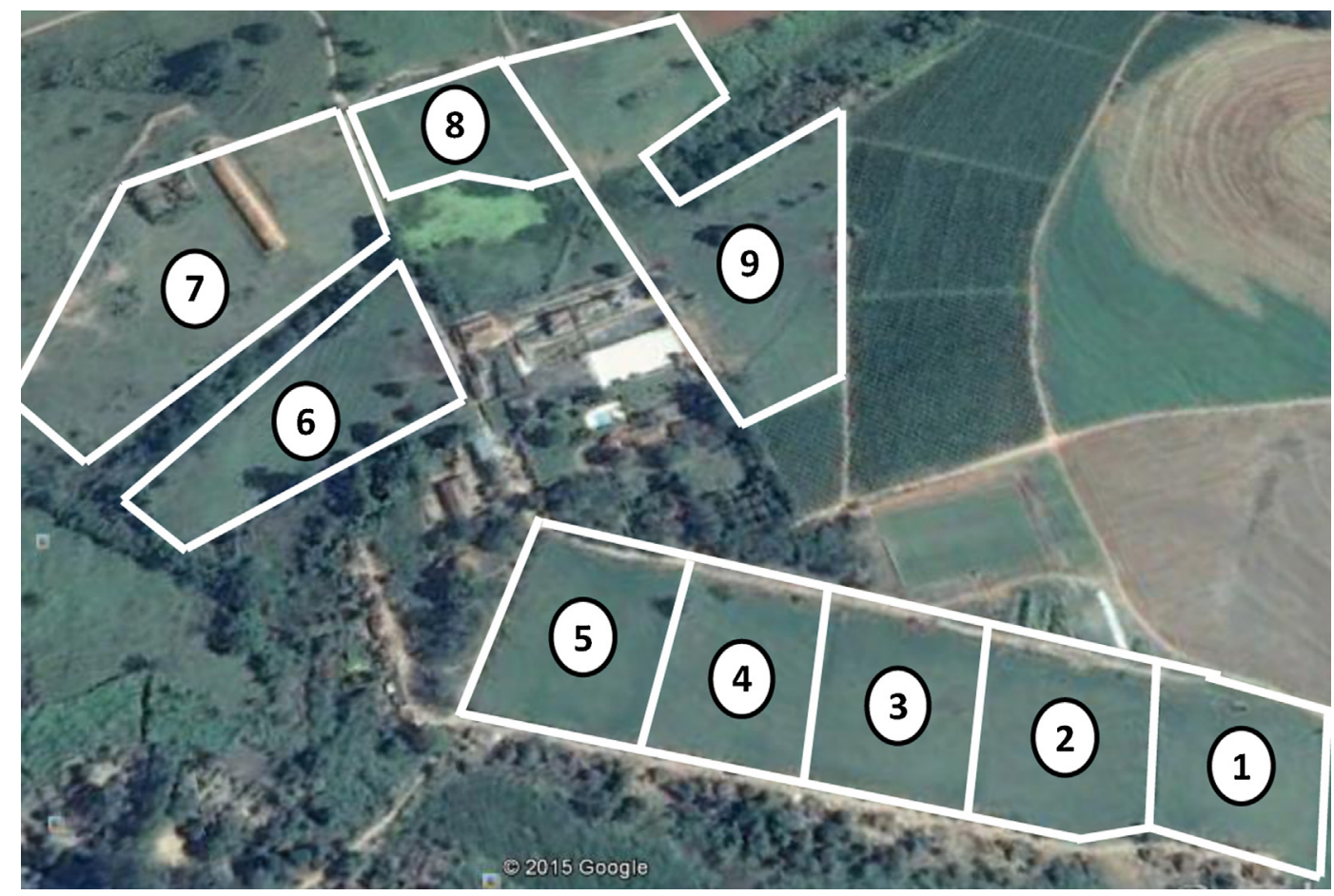

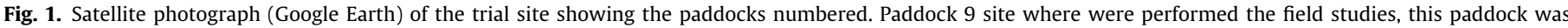

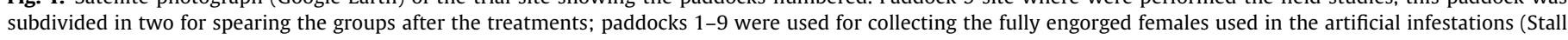
tests) and in the adult immersion tests. 
Table 1

Mean counts of female R. (B.) microplus (4.5-8.0-mm long) for control and treated cattle groups; efficacy percentages. Arithmetic means. Field study performed in 2005.

\begin{tabular}{|c|c|c|c|c|c|c|c|c|c|}
\hline \multicolumn{10}{|c|}{ Study performed in 2005} \\
\hline \multirow[t]{2}{*}{ Day of the study } & T01: control & \multicolumn{2}{|c|}{ (water) } & \multicolumn{3}{|c|}{ T02: amitraz $12.5 \%$} & \multicolumn{2}{|c|}{ ANOVA } & \multirow[t]{2}{*}{$\overline{\text { Efficacy(arithmetic mean) }}$} \\
\hline & \multicolumn{3}{|c|}{ Mean count ${ }^{\mathrm{a}} /$ range } & \multicolumn{3}{|c|}{ Mean count ${ }^{\mathrm{a}}$ /range } & $\mathrm{CV}^{\mathrm{c}}$ & $\operatorname{Pr}<F^{\mathrm{d}}$ & \\
\hline 0 & 42.4 & $11.3-104.7$ & A & 42.1 & $12-104.7$ & A & 16.79 & 0.9956 & - \\
\hline 3 & 37.5 & $16-93$ & A & 12.4 & $0-40$ & B & 29.09 & 0.0021 & 67 \\
\hline 7 & 37.3 & $18-103$ & A & 8.6 & $4-12$ & B & 15.48 & $<0.0001$ & 77 \\
\hline 14 & 43.4 & $22-94$ & A & 12.4 & $0-20$ & B & 32.12 & 0.0025 & 71 \\
\hline 21 & 45.0 & $26-100$ & A & 27.4 & $8-42$ & B & 12.76 & 0.0302 & 39 \\
\hline 28 & 46.2 & $23-103$ & A & 39.4 & $20-56$ & A & 10.33 & 0.4682 & 14 \\
\hline
\end{tabular}

a Means values followed by the same letter on the same line do not differ significantly at a 95\% reliability level.

b Commercial formulation purchased in the local market.

c Coefficient of variation.

d Probablility of significance $F$.

the treatment date, and " $\mathrm{Cb}$ " is the number of ticks counted on untreated control animals on the three days preceding treatment.

\subsection{R. (B.) microplus adult immersion tests}

To evaluate the sensitivity of the population of $R$. (B.) microplus from the farm where the field studies were performed, two in vitro tests (one in 2005 and the second in 2015) were conducted with the tested $12.5 \%$ amitraz formulation using fully engorged female ticks belonging to different paddocks (1-9) from the experimental farm.

Approximately 80 fully engorged females were separated during the collection of ticks to form the laboratory colonies. In each test (2005 and 2015), 40 ticks were used for each group: 20 (with two replications) were subjected to treatment with $12.5 \%$ amitraz and the remaining 20 (with two replications) were used as negative untreated controls. Subsequently, specimens were taken to the laboratory (CPPAR/FCAV/UNESP, Jaboticabal, São Paulo, Brazil), washed with running water and dried using paper towels. Then, the ticks were placed on a white tray for selection based on visual inspection of those that showed good mobility and repletion. Ticks that showed anomalies in size or shape were immediately discarded. To form groups for both tests, female ticks were ordered from the biggest to the smallest individuals, thereby allowing a similar final weight for each group to be determined.

Female ticks from each group for each test (2005 and 2015) were placed in $50 \mathrm{~mL}$ Falcon tubes and immersed in $20 \mathrm{~mL}$ solutions containing diluted $12.5 \%$ amitraz for $5 \mathrm{~min}$.

Next, the ticks were recovered on plastic strainers, dried using paper towels at room temperature for approximately $5 \mathrm{~min}$ and then transferred to plastic Petri dishes and moved to a biochemical oxygen demand (BOD) incubator at a temperature of $27^{\circ} \mathrm{C}$ and approximately $85 \%$ relative humidity to stimulate oviposition. Twenty days after oviposition in the BOD incubator, the egg masses of engorged female ticks were recorded for each group. Subsequently, the egg masses of each group were transferred to adapted $3 \mathrm{~mL}$ syringes and returned to the BOD incubator (at $27^{\circ} \mathrm{C}$ and approximately $85 \%$ relative humidity) to stimulate larval hatching. After 20 days of larval hatching in the BOD incubator, the percentage of hatchability was calculated according to a methodology described by Gonzales et al. (1993). The percentage of hatched eggs from each sample group and each test (2005 and 2015) was visually estimated using a stereo-microscope with an ocular grid to compare the proportion of larvae in relation to the proportion of unhatched eggs for each group and post-treatment day (Drummond et al., 1973; Gonzales et al., 1993; George and Davey, 2004; Holdsworth et al., 2006). The error of this hatching percentage analysis was estimated to be $5 \%$.

\subsection{Data analysis}

A "Split Plot in Time" design was used to analyze the tick counts obtained in the field trials and Stall tests. Treatments were considered the main parcels (with 10 or 6 replications each, depending on the trial), and the observational dates were considered the secondary parcels (Banzatto and Kronka, 1989). Data were examined using a methodology described by Little and Hills (1978), in which the data were $\log$ transformed $(x+1)$. Analyses were conducted using the F Test, and means were compared using the Tukey Test (SAS Institute, 1996).

\subsection{Criteria for the diagnosis of resistance or susceptibility of a tick population to amitraz}

According to EMEA (2004) and Holdsworth et al. (2006) with some exceptions, the control of a tick population by a specific formulation is considered unsatisfactory when the efficacy values of the compound are inferior to 90\%. Moreover, the Brazilian Ministry of Agriculture, Livestock and Food Supply (Ministério da Agricultura, Pecuária e Abastecimento; MAPA) through Ordinance $\mathrm{N}^{\circ} 48$ (Brazil, 1997) states the importance of considering the average efficacy of a formulation between days 7 and 14 post-treatment for field studies. In artificial infestation studies (Stall tests), the mean efficacy of a spray formulation should be calculated between days 1 and 23 post-treatment. A mean efficacy inferior to $90 \%$ between these dates was the criteria adopted to designate $R$. (B.) microplus as resistant to $12.5 \%$ amitraz (spray).

\section{Results}

No signs of abnormalities or systemic intoxication were observed in the experimental animals before or after the administration of $12.5 \%$ amitraz in all experiments. Moreover, no bovines died and no concomitant medications were administered during these experiments.

\subsection{5 trials}

The results of the $12.5 \%$ amitraz efficacy against $R$. (B.) microplus obtained from the 2005 field trial are described in Table 1. The analysis of these results demonstrated that amitraz reached efficacy indices of 67,77 and $71 \%$ on the 3rd, 7th and 14th days post-treatment (DPT), respectively. The acaricidal efficacy of the chemical decreased to 39 and $14 \%$ on days 21 and 28 posttreatment, respectively, when the tick counts for this study were concluded (Table 1). Based on the results of the statistical analysis, animals from the untreated control group were verified to present an average number of ticks that was significantly superior $(P \leq 0.05)$ 
Table 2

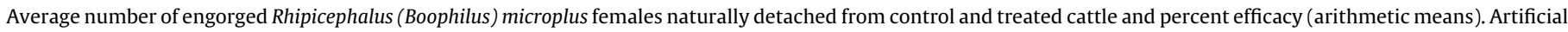
infestation (Stall test) of study performed in 2005.

\begin{tabular}{|c|c|c|c|c|c|c|c|c|c|}
\hline \multicolumn{10}{|c|}{ Study performed in 2005} \\
\hline \multirow[t]{2}{*}{ Day of the study } & \multicolumn{3}{|c|}{$\begin{array}{l}\text { T01: control } \\
\text { (water) }\end{array}$} & \multicolumn{3}{|c|}{ T02: amitraz $12.5 \%$} & \multicolumn{2}{|c|}{ ANOVA } & \multirow[t]{2}{*}{$\begin{array}{l}\text { Efficacy } \\
\text { (arithmetic mean) }\end{array}$} \\
\hline & \multicolumn{3}{|c|}{ Mean count ${ }^{\mathrm{a}} /$ range } & \multicolumn{3}{|c|}{ Mean count ${ }^{\mathrm{a}} /$ range } & $\mathrm{CV}^{\mathrm{c}}$ & $\operatorname{Pr}<F^{\mathrm{d}}$ & \\
\hline 0 & 81.67 & $31.67-119.0$ & A & 80.11 & $30.67-154.0$ & A & 13.30 & 0.9752 & - \\
\hline 1 & 28.67 & $12-50$ & A & 17.33 & $2-23$ & A & 23.69 & 0.2320 & 38 \\
\hline 2 & 40.17 & $21-67$ & A & 20.50 & $14-32$ & A & 11.28 & 0.0601 & 48 \\
\hline 3 & 91.33 & $30-197$ & A & 43.83 & $11-123$ & A & 21.13 & 0.0860 & 51 \\
\hline 4 & 332.33 & $42-867$ & A & 110.83 & $11-358$ & B & 24.20 & 0.0070 & 66 \\
\hline 5 & 580.00 & $162-1175$ & A & 164.00 & $45-423$ & B & 16.09 & 0.0181 & 71 \\
\hline 6 & 711.33 & $208-1549$ & A & 183.50 & $68-452$ & B & 14.03 & 0.0172 & 74 \\
\hline 7 & 748.33 & $204-1518$ & A & 199.83 & $93-380$ & B & 13.24 & 0.0216 & 73 \\
\hline 8 & 647.50 & $181-1386$ & A & 140.17 & $76-225$ & B & 12.74 & 0.0103 & 78 \\
\hline 9 & 606.17 & 177-1179 & A & 121.50 & $20-234$ & B & 15.67 & 0.0042 & 79 \\
\hline 10 & 159.00 & $32-198$ & A & 58.50 & $17-89$ & B & 17.54 & 0.0268 & 62 \\
\hline 11 & 114.17 & $36-252$ & A & 43.17 & $9-87$ & B & 21.13 & 0.0435 & 61 \\
\hline 12 & 99.83 & $34-178$ & A & 38.00 & $10-61$ & B & 17.92 & 0.0433 & 61 \\
\hline 13 & 168.83 & $58-296$ & A & 60.50 & $22-96$ & B & 13.00 & 0.0171 & 63 \\
\hline 14 & 161.83 & $61-350$ & A & 90.83 & $24-161$ & B & 14.53 & 0.0472 & 43 \\
\hline 15 & 138.50 & $56-235$ & A & 84.17 & $23-177$ & B & 16.11 & 0.0349 & 38 \\
\hline 16 & 140.67 & $41-295$ & A & 72.83 & $12-141$ & B & 20.25 & 0.0045 & 47 \\
\hline 17 & 170.33 & $44-316$ & A & 77.33 & $21-181$ & B & 17.17 & 0.0290 & 54 \\
\hline 18 & 151.83 & $45-292$ & A & 68.83 & $5-179$ & B & 24.33 & 0.0312 & 54 \\
\hline 19 & 240.67 & $125-454$ & A & 109.00 & $5-236$ & B & 21.78 & 0.0326 & 54 \\
\hline 20 & 226.83 & $90-435$ & A & 121.50 & $45-232$ & B & 12.68 & 0.0217 & 45 \\
\hline 21 & 203.00 & $78-431$ & A & 104.83 & $32-145$ & B & 13.38 & 0.0189 & 47 \\
\hline 22 & 201.50 & $79-421$ & A & 108.17 & $39-158$ & B & 17.88 & 0.0321 & 45 \\
\hline 23 & 198.50 & $81-401$ & A & 106.00 & $41-143$ & B & 13.47 & 0.0489 & 45 \\
\hline 24 & 200.83 & $84-412$ & A & 110.17 & $44-165$ & B & 21.35 & 0.0239 & 44 \\
\hline 25 & 203.83 & $89-425$ & A & 113.00 & $48-178$ & B & 18.21 & 0.0431 & 43 \\
\hline 26 & 200.33 & $75-418$ & A & 112.67 & $45-179$ & B & 14.59 & 0.0318 & 43 \\
\hline 27 & 197.33 & $71-404$ & A & 113.67 & $48-182$ & B & 12.39 & 0.0194 & 41 \\
\hline 28 & 197.17 & $65-409$ & A & 114.00 & $46-186$ & B & 11.32 & 0.0324 & 41 \\
\hline $1-23$ & 255.74 & $12-1549$ & A & 96.74 & $2-452$ & B & 12.36 & 0.0021 & 61 \\
\hline
\end{tabular}

a Means values followed by the same letter on the same line do not differ significantly at a 95\% reliability level.

b Commercial formulation purchased in the local market.

c Coefficient of variation.

d Probablility of significance $F$.

Table 3

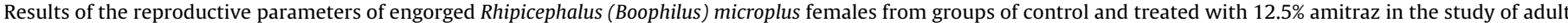
immersion tests. Reduction of oviposition, hatchability, reproductive efficiency and reproductive capacity.

\begin{tabular}{|c|c|c|c|c|c|c|c|c|c|c|}
\hline \multicolumn{11}{|c|}{ Study performed in 2005} \\
\hline \multirow[t]{2}{*}{ Test } & \multirow[t]{2}{*}{ Group } & \multirow[t]{2}{*}{ Repetition } & \multirow{2}{*}{$\begin{array}{l}\text { Number of } \\
\text { engorged } \\
\text { female } \\
\text { pre-selected }\end{array}$} & \multirow{2}{*}{$\begin{array}{l}\text { Engorged } \\
\text { female } \\
\text { weigth (g) }\end{array}$} & \multirow{2}{*}{$\begin{array}{l}\text { Egg mass } \\
\text { weight }(\mathrm{g})\end{array}$} & \multirow{2}{*}{$\begin{array}{l}\text { Hatchability } \\
(\%)\end{array}$} & \multicolumn{2}{|l|}{ \%Reduction } & \multirow{2}{*}{$\begin{array}{l}\text { Reproductive } \\
\text { efficiency }\end{array}$} & \multirow{2}{*}{$\begin{array}{l}\text { Reproductive } \\
\text { capacity (\%) }\end{array}$} \\
\hline & & & & & & & Oviposition (\%) & Hatchability (\%) & & \\
\hline \multirow[t]{6}{*}{ A } & Control & 1 & 10 & 2.021 & 0.521 & 99.6 & - & - & 513524 & - \\
\hline & & 2 & 10 & 2.045 & 0.512 & 99.4 & - & - & 497729 & - \\
\hline & Mean & & 10 & 2.033 & 0.517 & 99.5 & - & - & 505576 & - \\
\hline & $12.5 \%$ amitraz & 1 & 10 & 2.029 & 0.334 & 34.0 & 36.0 & 66.0 & 111937 & - \\
\hline & & 2 & 10 & 2.115 & 0.435 & 46.0 & 17.0 & 54.0 & 189220 & - \\
\hline & Mean & & 10 & 2.072 & 0.385 & 40.0 & 26.0 & 60.0 & 150578 & 70 \\
\hline
\end{tabular}

to the average amount of $R$. (B.) microplus quantified in bovines treated with amitraz between the 3rd and 21st DPT (Table 1).

The results obtained from the artificial infestation trial conducted in 2005 with this same tick strain reiterated the efficacy values against $R$. (B.) microplus obtained from the field trial. In the Stall test, amitraz reached a maximum efficacy index of $79 \%$ on the 9th DPT. Subsequent evaluation dates saw a constant decrease in efficacy, which reached $41 \%$ on the 28 th DPT, leading to the end of this experiment (Table 2). Mean tick counts from the control group were significantly superior $(P \leq 0.05)$ to the mean $R$. (B.) microplus counts from the animals treated with $12.5 \%$ amitraz between days 4 and 28 post-treatment (Table 2 ).

Using the efficacy indices of the $12.5 \%$ amitraz formulation obtained from the adult immersion tests, we verified that this compound showed $70 \%$ efficacy towards the reproductive parameters of fully engorged $R$. (B.) microplus females (Table 3).

Analysis of these results based on the resistance diagnosis criteria pre-established for this experiment demonstrated that the tested $R$. (B.) microplus population was resistant to $12.5 \%$ amitraz administered through whole body spraying in all three trials conducted (field study, Stall test and adult immersion test). 
Table 4

Mean counts of female R. (B.) microplus (4.5-8.0-mm long) for control and treated cattle groups; efficacy percentages. Arithmetic means. Field study performed in 2015 .

\begin{tabular}{|c|c|c|c|c|c|c|c|c|c|}
\hline \multicolumn{10}{|c|}{ Study performed in 2015} \\
\hline \multirow[t]{2}{*}{ Day of the study } & T01: control & \multicolumn{2}{|c|}{ (water) } & \multicolumn{3}{|c|}{ T02: amitraz $12.5 \%{ }^{\mathrm{b}}$} & \multicolumn{2}{|c|}{ ANOVA } & \multirow[t]{2}{*}{ Efficacy(arithmetic mean) } \\
\hline & \multicolumn{3}{|c|}{ Mean count $\mathrm{t}^{\mathrm{a}} /$ range } & \multicolumn{3}{|c|}{ Mean count ${ }^{\mathrm{a}} /$ range } & $\mathrm{CV}^{\mathrm{c}}$ & $\operatorname{Pr}<F^{\mathrm{d}}$ & \\
\hline 0 & 36.9 & $22.1-77.0$ & A & 37.3 & $22.4-77.7$ & A & 12.89 & 0.9550 & - \\
\hline 3 & 38.6 & $18-98$ & A & 18.5 & $10-57$ & B & 16.06 & 0.0084 & 52 \\
\hline 7 & 40.4 & $21-103$ & A & 17.9 & $10-58$ & $\mathrm{~B}$ & 16.89 & 0.0060 & 56 \\
\hline 14 & 43.6 & $18-90$ & A & 20.2 & $7-51$ & B & 15.26 & 0.0051 & 53 \\
\hline 21 & 46.3 & $21-101$ & A & 30.3 & $17-54$ & $\mathrm{~B}$ & 11.38 & 0.0387 & 34 \\
\hline 28 & 47.5 & 19-98 & A & 40.5 & $25-75$ & A & 11.00 & 0.4143 & 14 \\
\hline
\end{tabular}

a Means values followed by the same letter on the same line do not differ significantly at a 95\% reliability level.

b Commercial formulation purchased in the local market.

c Coefficient of variation.

d Probablility of significance $F$.

Table 5

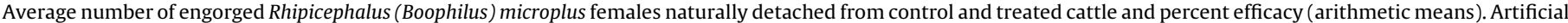
infestation (Stall test) of study performed in 2015.

\begin{tabular}{|c|c|c|c|c|c|c|c|c|c|}
\hline \multicolumn{10}{|c|}{ Study performed in 2015} \\
\hline \multirow[t]{2}{*}{ Day of the study } & T01: control & \multicolumn{2}{|l|}{ (water) } & \multicolumn{3}{|c|}{ T02: amitraz $12.5 \%$} & \multicolumn{2}{|c|}{ ANOVA } & \multirow[t]{2}{*}{ Efficacy(arithmetic mean) } \\
\hline & \multicolumn{3}{|c|}{ Mean count ${ }^{\mathrm{a}} /$ range } & \multicolumn{3}{|c|}{ Mean count ${ }^{\mathrm{a}} /$ range } & \multirow{2}{*}{$\begin{array}{r}\mathrm{CV}^{\mathrm{c}} \\
8.56\end{array}$} & \multirow{2}{*}{$\begin{array}{l}\operatorname{Pr}<F^{\mathrm{d}} \\
0.9908\end{array}$} & \\
\hline 0 & 49.23 & $34.70-74.70$ & A & 49.78 & $29.70-74.30$ & A & & & - \\
\hline 1 & 50.50 & 21-83 & A & 49.33 & 27-103 & A & 15.35 & 0.9164 & 3 \\
\hline 2 & 51.17 & $29-76$ & A & 43.83 & $22-98$ & A & 12.58 & 0.4761 & 15 \\
\hline 3 & 52.33 & $32-82$ & A & 39.00 & $17-84$ & A & 12.79 & 0.2530 & 26 \\
\hline 4 & 53.17 & 27-91 & A & 31.00 & $13-69$ & A & 15.75 & 0.1328 & 42 \\
\hline 5 & 53.33 & $19-96$ & A & 24.50 & $11-63$ & A & 19.37 & 0.0790 & 55 \\
\hline 6 & 54.50 & $23-102$ & A & 20.83 & $8-58$ & B & 21.62 & 0.0400 & 62 \\
\hline 7 & 55.17 & 23-99 & A & 18.83 & $5-54$ & B & 24.13 & 0.0285 & 66 \\
\hline 8 & 55.00 & $26-82$ & A & 27.50 & $8-61$ & B & 19.43 & 0.0444 & 51 \\
\hline 9 & 55.67 & $28-88$ & A & 33.50 & $11-73$ & A & 17.20 & 0.1370 & 40 \\
\hline 10 & 55.33 & $29-81$ & A & 33.50 & $13-74$ & A & 15.40 & 0.1182 & 40 \\
\hline 11 & 55.83 & $26-87$ & A & 35.83 & $13-76$ & A & 14.61 & 0.1682 & 37 \\
\hline 12 & 55.67 & $28-118$ & A & 30.67 & $10-72$ & A & 20.42 & 0.2696 & 46 \\
\hline 13 & 55.00 & 25-105 & A & 29.17 & $9-75$ & A & 21.73 & 0.2248 & 48 \\
\hline 14 & 55.83 & $16-123$ & A & 24.00 & $6-67$ & A & 25.06 & 0.1356 & 57 \\
\hline 15 & 55.33 & $21-112$ & A & 33.00 & $8-58$ & A & 18.82 & 0.4411 & 57 \\
\hline 16 & 53.50 & 26-103 & A & 37.67 & $6-98$ & A & 23.34 & 0.4034 & 49 \\
\hline 17 & 53.33 & $28-102$ & A & 39.17 & 4-98 & A & 29.85 & 0.3144 & 50 \\
\hline 18 & 52.17 & 28-95 & A & 35.33 & 11-99 & A & 18.91 & 0.2212 & 45 \\
\hline 19 & 52.83 & $26-98$ & A & 38.00 & $8-88$ & A & 19.25 & 0.3049 & 40 \\
\hline 20 & 53.50 & $31-93$ & A & 29.17 & $6-87$ & A & 21.08 & 0.0805 & 46 \\
\hline 21 & 52.83 & $27-88$ & A & 32.50 & $12-56$ & A & 14.25 & 0.1407 & 37 \\
\hline 22 & 57.67 & $21-98$ & A & 34.17 & $13-65$ & A & 21.03 & 0.3021 & 38 \\
\hline 23 & 56.50 & $23-93$ & A & 32.67 & $15-54$ & A & 17.04 & 0.1234 & 35 \\
\hline 24 & 59.00 & $20-90$ & A & 34.67 & $16-65$ & A & 32.45 & 0.3256 & 34 \\
\hline 25 & 54.00 & 24-98 & A & 36.17 & $14-76$ & A & 18.56 & 0.4532 & 34 \\
\hline 26 & 55.00 & 27-94 & A & 36.00 & $13-76$ & A & 24.56 & 0.2876 & 32 \\
\hline 27 & 58.00 & $23-97$ & A & 36.67 & $16-77$ & A & 23.32 & 0.2945 & 32 \\
\hline 28 & 56.67 & $26-90$ & A & 36.33 & $18-73$ & A & 25.31 & 0.4567 & 37 \\
\hline $1-23$ & 53.75 & $16-123$ & A & 31.74 & 4-103 & A & 23.43 & 0.4921 & 42 \\
\hline
\end{tabular}

a Means values followed by the same letter on the same line do not differ significantly at a 95\% reliability level.

b Commercial formulation purchased in the local market.

c Coefficient of variation.

d Probablility of significance $F$.

\subsection{5 trials}

After 10 years, the results from the second field trial conducted showed that $12.5 \%$ amitraz obtained efficacy indices of 52, 56, 53, 34 and $14 \%$ on days $3,7,14,21$ and 28 post-treatment, respectively. The statistical analysis verified that the average tick counts from the control group animals were significantly superior $(P \leq 0.05)$ to those obtained from bovines that belonged to the group treated with amitraz between the 3rd and 21st DPT (Table 4).
In the Stall tests conducted with artificially infested bovines, amitraz reached maximum efficacy indices of 66 and $66 \%$ on the 6 th and 7th DPT, respectively. Between the 9th and 20th DPT, the chemical compound presented efficacy values between 36 and 57\% (Table 5). Between days 21 and 28 post-treatment, the amitraz efficacy remained approximately $30 \%$, with $37 \%$ obtained on the 28 th DPT when the trial was concluded. Statistical analysis of the data verified that the untreated animals presented $R$. (B.) microplus averages that were significantly superior $(P \leq 0.05)$ to those obtained 
Table 6

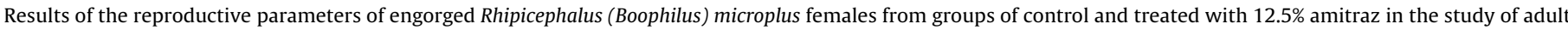
immersion tests. Reduction of oviposition, hatchability, reproductive efficiency and reproductive capacity.

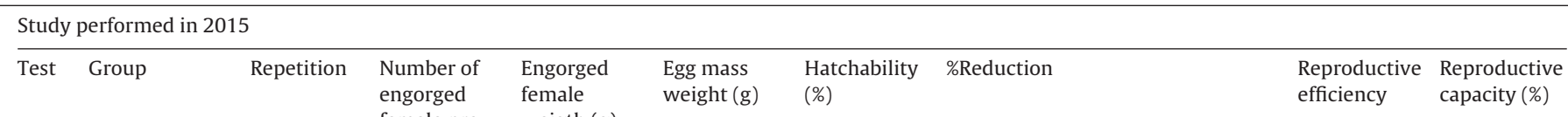

female pre- $\quad$ weigth $(\mathrm{g})$

selected

Oviposition (\%) Hatchability (\%)

\begin{tabular}{|c|c|c|c|c|c|c|c|c|c|c|}
\hline \multirow[t]{6}{*}{ A } & Control & 1 & 10 & 1.984 & 0.492 & 99.8 & - & - & 494976 & - \\
\hline & & 2 & 10 & 1.903 & 0.491 & 99.7 & - & - & 514425 & - \\
\hline & Mean & & 10 & 1.944 & 0.492 & 99.8 & - & - & 504498 & - \\
\hline & $12.5 \%$ amitraz & 1 & 10 & 1.932 & 0.321 & 47.0 & 35.0 & 53.0 & 156180 & - \\
\hline & & 2 & 10 & 1.980 & 0.378 & 58.0 & 23.0 & 42.0 & 221660 & - \\
\hline & Mean & & 10 & 1.956 & 0.350 & 52.2 & 29.0 & 47.0 & 188920 & 62 \\
\hline
\end{tabular}

from bovines treated with amitraz between post-treatment days 6 and 8 (Table 5).

In the in vitro adult immersion tests, the formulation containing $12.5 \%$ showed $62 \%$ efficiency over the reproductive parameters of R. (B.) microplus females (Table 6).

Using the resistance diagnosis criteria adopted for the present study, we verified through trials conducted after a 10-year gap (2005-2015, comprising approximately 40 tick generations with no contact to amidines) that this $R$. (B.) microplus population remained resistant to $12.5 \%$ amitraz administered via whole body spraying in all of the trials conducted (field study, Stall test and adult immersion test).

\section{Discussion}

Brazil is a huge country with very different climatic regions (South, Southeast, Center-West, North and Northeast) where the temperature, relative humidity and pluviometric precipitation indices are different. These conditions directly alter the number of $R$. (B.) microplus generations in each of these regions. The location in which the present study was conducted (Southeast region of Brazil) was characterized by two distinct climate phases: one rainy season with high temperatures and humidity, which occurs during the spring and summer (October and March), and one season with inferior temperatures with low rain and relative humidity, which occurs during autumn and winter (April and September). $R$. (B.) microplus population dynamic studies in this same region of Brazil were conducted by Kasai et al. (2000) and Pereira et al. (2008). Both studies demonstrated that this tick species presented an average of 4 generations per year. Gomes (2014) evaluated the population dynamic of this same tick species in Minas Gerais, a state also located on the Southeast region of Brazil, and reported 5 generations per year. This result demonstrated that nearly 40 generations of this tick species remained free from any contact with amitraz and/or any other formamidine derivates between 2005 and 2015, which was period between both parts of this study.

Amitraz has been in use since 1975 in Australia, and the first case of resistance to this chemical in this country was reported in 1981 (Nolan, 1981). In Mexico, amitraz was introduced in 1986 and the first case of resistance was diagnosed in 2001 (Soberanes Cespedes et al., 2002). In Brazil, this compound was introduced in 1987 and the first case of resistance was diagnosed in 1994 by Francisco Branco (reported by Martins et al., 2003). Resistance to amitraz is now a problem for cattle producers around the world and has been reported in various locations including Australia (Jonsson and Hope, 2007), Mexico (Rodriguez-Vivas et al., 2006), Brazil (Li et al., 2005; Martins et al., 2003; Santos et al., 2013) and New Caledonia (Chevillon et al., 2007). The prevalence of resistance to amitraz was estimated to be $11 \%$ in Australia (Jonsson and Hope, 2007) and 19.4\% in Mexico (Rodriguez-Vivas et al., 2006). Although resistance to the product was not widespread, it was the mainstay of tick control in many countries due to its high efficacy and relatively low cost (Jonsson and Matschoss, 1998).

To date, loss of resistance to amitraz has not been documented after removal of selection pressure. The only two studies that examined the effect of selection with amitraz in the field were published by Rosado-Aguilar et al. (2008) and Jonsson et al. (2010). In the first study, a monthly application of amitraz was shown to increase resistance ratios from one- or two-fold to over 10 -fold within 15 months. The effect after this time period was not reported. The second trial was performed by Jonsson et al. (2010) and evaluated the rotation of treatments between spinosad and amitraz to control $R$. (B.) microplus populations with amitraz resistance.

In this case, the study was conducted over 4 years in which three treatments were applied to 6 groups of Holstein dairy calves. Standard counts of all ticks between 4.5 and $8.0 \mathrm{~mm}$ in diameter on one side of each animal were made each week, and treatment was applied when the tick numbers exceeded a threshold of 25 engorged adults per side. The three treatments were: 1 , spinosad spray whenever tick numbers exceeded the threshold; 2 , amitraz spray whenever tick numbers exceeded the threshold; and 3, spinosad whenever tick numbers exceeded the threshold. These treatments were performed for the first 2 months, followed by amitraz for 2 months, with alternations every subsequent 2 months. The larval packet test bioassay was used to diagnose acaricide resistance to amitraz. These authors concluded that treatment with spinosad or with a rotation between spinosad and amitraz every 2 months resulted in the loss of evidence of amitraz resistance on the LPT and a return to full or almost full susceptibility to amitraz. In accordance with these results, rotation strategies using amitraz should be developed with caution because secondary mutations could negate the measured loss in amitraz resistance shown in the study. It should also be noted that a similar loss of resistance is measurable in the geographical location where the rotation program will be implemented. Areas with little seasonal climatic variation might not drive similar selection pressures against amitraz-resistant ticks (Jonsson et al., 2010).

In addition to the aforementioned field trials, the possibility of reutilizing amitraz in a field strain has been proposed. Furlong et al. (2007) stated that the amidine group was the only acaricide group that allowed for a regression of resistance. The authors claimed that nearly 15-20 generations of ticks not exposed to selection pressure by the use of products of this family would allow for a reutilization of these chemicals. Spagnol et al. (2010) correlated the difference in efficacy values obtained by amitraz use in Brazil (49-99\%) with a possible amidine resistance reversion after a period without the administration of this product against a field strain.

The results described in the present study regarding the reutilization of amitraz against $R$. (B.) microplus differed from those obtained by Jonsson et al. (2010) in Australia. One possibility that 
might justify this discrepancy was provided by Estrada-Peña et al. (2012). These authors reported that the Australian cattle tick Rhipicephalus australis Fuller was reinstated based on adults and larvae redescribed from material collected in Australia.

This long ignored boophilid was previously known as Rhipicephalus microplus Canestrini for specimens reported in Australia and New Caledonia. The use of principal components analysis on body measurements led to a clear separation of larvae of both taxa. A phylogenetic analysis based on 12S- and 16S-rDNA gene sequences supports the conspecific nature of the neotype material on which the reinstatement of the species is proposed and of the specimens used for previous interspecific crosses. $R$. australis is now known to be present in Australia, New Caledonia, the island of Borneo, Philippines, Sumatra, Java, New Guinea, Cambodia, and Tahiti. Finally, the authors conclude that despite these consequences, the lack of reliable data on Madagascan specimens and the limited number of strains used for the molecular and crossbreeding work by Labruna et al. (2009), there is now more than sufficient supporting evidence for the taxonomic separation of $R$. australis and $R$. microplus (Estrada-Peña et al., 2012). However, future studies are needed to confirm this hypothesis.

Based on the obtained results, it is possible to conclude that a period of three consecutive years (2002-2004) of rotation of amitraz and pyrethroids every 28 days before the initiation of the present study was sufficient to create an amitraz resistance situation for this particular R. (B.) microplus strain. Moreover, with the aid of field trials, artificial infestation Stall tests and adult immersion tests, we verified that nearly 40 tick generations without any contact to the tested compound (amitraz) were not sufficient to revert or modify the resistance/efficacy situation of this $R$. (B.) microplus strain against amitraz. It is possible that reversion in amitraz efficacy values in a $R$. (B.) microplus population occurs when resistance of this field strain is incipient in a tick population. An alternative explanation is that perhaps the tested Rhipicephalus spp. species are different in the trials conducted to date. Therefore, future studies should be performed to confirm these hypotheses.

\section{Conflicts of interest}

There were no conflicts of interest that may have biased the work reported in this paper.

\section{References}

Banzatto, D.A., Kronka, S.N., 1989. Experimentação Agrícola. FUNEP, Jaboticabal, pp. 1989.

Brazil, 1997. Ministério da Agricultura e Abastecimento. Secretaria de Defesa Agropecuária, Portaria, n 48 (12/05/1997).

Chevillon, C., Ducornez, S., de Meeus, T., Koffi, B.B., Gaia, H., Delathiere, J.M., Barre, N., 2007. Accumulation of acaricide resistance mechanisms in Rhipicephalus (Boophilus) microplus (Acari: Ixodidae) populations from New Caledonia Island. Vet. Parasitol. 147, 276-288.

Corrêa, R.R., Lopes, W.D.Z., Teixeira, W.F.P., Cruz, B.C., Gomes, L.V.C., Felippelli, G., Maciel, W.G., Favero, F., Buzzulini, C., Bichuette, M.A., Soares, V.E., Costa, A.J., 2015. A comparison of three different methodologies for evaluating Rhipicephalus (Boophilus) microplus susceptibility to topical spray compounds. Vet. Parasitol. 207, 115-124.

Cruz, B.C., Teixeira, W.F.P., Maciel, W.G., Felippelli, G., Favero, F.C., Cruz, A.C., Buzzulini, C., Soares, V.E., Gomes, L.V.C., Lopes, W.D.Z., Oliveira, G.P., Costa, A.J., 2014a. Effects of fluazuron $(2.5 \mathrm{mg} / \mathrm{kg})$ and a combination of fluazuron $(30 \mathrm{mg} / \mathrm{kg})+$ abamectin $(0.5 \mathrm{mg} / \mathrm{kg})$ on the reproductive parameters of afield population of Rhipicephalus (Boophilus) microplus on experimentally infested cattle. Res. Vet. Sci. 97, 80-84

Cruz, B.C., Lopes, W.D.Z., Maciel, W.G., Felippelli, G., Teixeira, W.F.P., Fávero, F.C., Prando, L., Buzzulini, C., Soares, V.E., Gomes, L.V.C., Bichuette, M.A., Costa, A.J., 2014b. Effect of a spray formulation on the reproductive parameters of a susceptible population of Rhipicephalus (Boophilus) microplus. Rev. Bras. Parastol. Vet. 23, 421-427.

Cruz, B.C., Lopes, W.D.Z., Maciel, W.G., Felippelli, G., Favero, F.C., Teixeira, W.F.P., Carvalho, R.S., Ruivo, M.A., Colli, M.H.A., Sakamoto, C.A.M., Costa, A.J., Oliveira, G.P., 2015. Susceptibility of Rhipicephalus (Boophilus) microplus to ivermectin $(200,500$ and $630 \mathrm{~g} / \mathrm{kg})$ in field studies in Brazil. Vet. Parasitol. 207, 309-317.
Dobson, R.J., Sangster, N.C., Besier, R.B., Woodgate, R.G., 2009. Geometric means provide a biased efficacy result when conducting a faecal egg count reduction test (FECRT). Vet. Parasitol. 161, 162-167.

Drummond, R.O., Ernst, S.E., Trevino, J.L., Gladney, W.J., Grsham, O.H., 1973. Boophilus annulatus and Boophilus microplus: laboratory tests of insecticides. J. Econ. Entomol. 66, 130-133.

EMEA., 2004. Guideline on Specific Efficacy Requirements for Ectoparasiticides in Cattle, Londres, [s.n.] p.10.

Estrada-Peña, A., Venzal, J.M., Nava, S., Mangold, A., Gugliemone, A.A., Labruna, M.B., Fuente, J., 2012. Reinstatement of Rhipicephalus (Boophilus) australis (Acari: Ixodidae) with redescription of the adult and larval stages. Entomol. Soc. Am. 49, 794-802.

Farias, N.A.R., Ruas, J.L., Santos, T.R.B., 2008. Análise da eficácia de acaricidas sobre o carrapato Boophilus microplus durante a última década, na região sul do Rio Grande do Sul. Cienc. Rural 38, 1700-1704.

Foil, L.D., Coleman, P., Eisler, M., Fragoso-Sanchez, H., Garcia-Vasquez, Z., Guerrero, F.D., Jonsson, N.N., Langstaff, I.G., Li, A.Y., Machila, N., Miller, R.J., Morton, J., Pruett, J., Torr, S., 2004. Factors that influence the prevalence of acaricide resistance and tick-borne diseases. Vet. Parasitol. 125, 163-181.

Furlong, J., Martins, J.R.S., Prata, M.C.A., 2007. O carrapato dos bovinos e a resistência: temos o que comemorar? Hora Vet. 159, 1-7.

George, J.E., Davey, R.B., 2004. Therapeutic and persistent efficacy of a single application of doramectin applied either as a pour-on of injection to cattle infested with Boophipuls microplus (Acari-Ixodidae). J. Med. Entomol. 41, 402-407.

Gomes, L.V.C., 2014. Dinâmica Populacional de Rhipicephalus (Boophilus) microplus (CANESTRINI, 1887) em Bovinos Mestiços, Mantidos em Pastagens de Brachiaria decumbens no Município de Formiga, Minas Gerais. Universidade Estadual Paulista. Dissertação de Mestrado, pp. 72.

Gomes, L.V.C., Lopes, W.D.Z., Cruz, B.C., Teixeira, W.F.P., Felippelli, G., Bichuette, M.A., Ruivo, M.A., Colli, M.H.A., Carvalho, R.S., Martinez, A.C., Soares, V.E., Costa, A.J., 2015. Acaricidal effects of fluazuron $(2.5 \mathrm{mg} / \mathrm{kg})$ and a combination of fluazuron $(1.6 \mathrm{mg} / \mathrm{kg})+$ ivermectin $(0.63 \mathrm{mg} / \mathrm{kg})$ administered at different routes, against Rhipicephalus (Boophilus) microplus parasitizing cattle. Exp. Parasitol. 153, 22-28.

Gonzales, J.C., Muniz, R.A., Farias, A., Gonçalves, L.C.B., Rew, R.S., 1993. Therapeutic and persistent efficacy of doramectin against Boophilus microplus in cattle. Vet. Parasitol. 49, 107-119.

Holdsworth, P.A., Kemp, D., Green, P., Peter, R.J., De Bruin, C., Jonsson, N.N., Letonja T., Rehbein, S., Vercruysse, J., 2006. World Association for the Advancement of Veterinary Parasitology (W.A.A.V.P.) guidelines for evaluating the efficacy of acaricides against ticks (Ixodidae) on ruminants. Vet. Parasitol. 136, 29-43.

Jonsson, N.N., Matschoss, A.L., 1998. Attitudes and practices of Queens-land dairy farmers to the control of the cattle tick, Boophilus microplus. Aust. Vet. J. 76, 746-751.

Jonsson, N.N., Hope, M., 2007. Progress in the epidemiology and diagnosis of amitraz resistance in the cattle tick Boophilus microplus. Vet. Parasitol. 146, 193-198.

Jonsson, N.N., Millerd, R.J., Kemp, D.H., Knowlesd, A., Ardila, A.E., Verrall, R.G., Rothwell, T., 2010. Rotation of treatments between spinosad and amitraz for the control of Rhipicephalus (Boophilus) microplus populations with amitraz resistance. Vet. Parasitol. 169, 157-164.

Kasai, N., Labruna, M.B., Pires, A.V., Louvandini, H., Aballa, A.L., Gennari, S.M., 2000. Dinâmica populacional de Boophilus microplus (Canestrini, 1887) em bovinos leiteiros mantidos em manejo de pastejo rotativo de capim-elefante. Arq. Bras. Med. Vet. Zootec. 52, 13-19.

Labruna, M.B., Naranjo, V., Mangold, A., Thompson, C., Estrada-Pena, A., Guglielmone, A.A., Jongejan, F., de la Fuente, J., 2009. Allopatric speciation in ticks: genetic and reproductive divergence between geographic strains of Rhipicephalus (Boophilus) microplus. BMC Evol. Biol. 9, 46-58.

Li, A.Y., Davey, R.B., Miller, R.J., George, J.E., 2005. Mode of inheritance of amitraz resistance in a Brazilian strain of the southern cattle tick, Boophilus microplus (Acari: Ixodidae). Exp. Appl. Acarol. 37, 183-198

Little, T.M., Hills, F.J., 1978. Agricultural Experimentation Design and Analysis. Wiley, New York, pp. 350.

Lopes, W.D.Z., Teixeira, W.F.P., Matos, L.V.S., Felippelli, G., Cruz, B.C., Maciel, W.G., Buzzulini, C., Fávero, F.C., Soares, V.E., Oliveira, G.P., Costa, A.J., 2013. Effects of macrocyclic lactones on the reproductive parameters of engorged Rhipicephalus (Boophilus) microplus females detached from experimentally infested cattle. Exp. Parasitol. 135, 72-78.

Lopes, W.D.Z., Teixeira, W.F.P., Felippelli, G., Cruz, B.C., Maciel, W.G., Soares, V.E., Santos, T.R., Matos, L., Favero, F., Costa, A.J., 2014. Assessing resistance of ivermectin and moxidectin against nematodes in cattle naturally infected using three different methodologies. Res. Vet. Sci. 96, 133-138.

Martins, J.R.S., Correa, B.L., Cereser, V.H., Arteche, C.C.P.A., 2003. Anais: Seminário Internacional de Parasitologia animal, Acapulco1-8.

Maza, A.P., Pinto, I.S.B., Fonseca, I., Antunes, G.R., Monteiro, C.M.O., Daemon, E., Muniz, M.S., Martins, M.F., Furlong, J., Prata, M.C.A., 2013. A new approach to characterization of the resistance of populations of Rhipicephalus microplus (Acari: Ixodidae) to organophosphate and pyrethroid in the state of Minas Gerais, Brazil. Exp. Parasitol. 134, 519-523.

Nolan, J., 1981. Current developments in resistance to amidine and pyrethroid tickicides in Australia. In: Whitehead, G., Gibson, B.J.D. (Eds.), Proceedings of Tick Biology and Control Conference. Tick Research Unit, Rhodes University, Grahamstown, South Africa, pp. 109-114. 
Pereira, M.C., Labruna, M.B., Szabó, M.P.J., Klafke, G.M., 2008. Rhipicephalus (Boophilus) microplus-biologia, controle e resistência, São Paulo. MedVet 1, 169.

Rodriguez-Vivas, R.I., Rodriguez-Arevalo, F., Alonso-Diaz, M.A., Fragoso-Sanchez, H., Santamaria, V.M., Rosario-Cruz, R., 2006. Prevalence and potential risk factors for amitraz resistance in Boophilus microplus ticks in cattle farms in the state of Yucatan, Mexico. Prev. Vet. Med. 75, 280-286.

Rosado-Aguilar, J.A., Rodriguez-Vivas, R.I., Garcia-Vasquez, Z., Fragoso-Sanchez, H. Ortiz-Najera, A., Rosario-Cruz, R., 2008. Development of amitraz resistance in field populations of Boophilus microplus (Acari: Ixodidae) undergoing typical amitraz exposure in the Mexican tro-pics. Vet. Parasitol. 152, 349-353.

Santos, T.R.B., Pappen, F.G., Farias, N.A.R., Vaz Jr., I.S., 2009. Análise in vitro da eficácia do amitraz sobre populações de Rhipicephalus (Boophilus) microplus Canestrini, 1887) da região sul do Rio Grande do Sul. Rev. Bras. Parasitol. Vet. $18,54-57$.

Santos, T.R.B., Klafke, G.M., Pappen, F.G., Nizoli, L.Q., Biegelmeyer, P., Farias, N.A.R., 2013. Comparison of three larval bioassays to evaluate susceptibility of Rhipicephalus (Boophilus) microplus to amitraz. Rev. Bras. Parasitol. Vet. 22 495-501.
SAS Institute, 1989-1996. SAS ${ }^{\circledR}$ User’s Guide: Estatistics, SAS Institute, Inc., Cary, NC, USA.

Soberanes Cespedes, N., Santamaria Vargas, M., Fragoso-Sanchez, H.,

Garcia-Vasquez, Z., 2002. First case reported of amitraz resistance in the cattle tick Boophilus microplus in Mexico. Teć. Pecu. Mex́. 40, 81-92.

Spagnol, F.H., Paranhos, E.B., Albuquerque, G.R., 2010. Avaliação in vitro da ação de acaricidas sobre Rhipicephalus (Boophilus) microplus Canestrini, 1887 (Acari: Ixodidae) de bovinos leiteiros no município de Itamaraju, Bahia, Brasil. Cienc. Anim. Bras. 11, 32-37

Vargas, M.S., Céspedes, N.S., Sánchez, H.F., Martins, J.R., Céspedes, C.O.C., 2003. Avaliação in vitrode uma cepa de campo de Boophilus microplus (Acari: Ixodidae) resistente à Amitraz. Cienc. Rural 33, 737-742.

Vercruysse, J., Albonico, M., Behnke, J., Kotze, A.C., Prichard, R.K., McCartly, J.S., Monitresor, A., Levecke, B., 2011. Is the antihelmintic resistance a concern for the control of human soil-transmitted helminths? Int. J. Parasitol. Drugs Drug Resist. 4, 14-27.

Wharton, R.H., Utech, K.B.W., 1970. Relation between engorgement and dropping of Boophilus microplus to assessment of tick number in cattle. Aust. Entomol. Soc. 9, 171-182. 